\title{
Platinum-Based Chemotherapy Secures Effective Local Control for Very Advanced Hereditary Triple-Negative Breast Cancer with Life-Threatening Bleeding
}

\author{
Arvids Irmejs ${ }^{1}$, Peteris Loza ${ }^{2}$, Elina Skuja ${ }^{1}$, Janis Gardovskis ${ }^{3}$ \\ 1. Institute of Oncology, Continuing Education, Riga Stradins University, Latvia 2. Breast Unit, Riga \\ Stradins University Hospital, Riga Stradins University, Latvia 3. Chief of Surgical Department, Riga \\ Stradins University Hospital, Riga Stradins University, Latvia
}

$\square$ Corresponding author: Peteris Loza, peteris.loza@stradini.lv

Disclosures can be found in Additional Information at the end of the article

\section{Abstract}

Here we report the case of a noncompliant 50-year-old female patient with high-grade, triplenegative breast cancer (TNBC) and strong family cancer history. She only agreed to start treatment after being admitted to the hospital with advanced stage disease and severe anaemia resulting from bulky, ulcerated, and actively bleeding tumor. Therapy was promptly started with platinum-based chemotherapy, resulting in extremely rapid clinical remission and complete control of local symptoms. In conclusion, we hypothesise that even a single course of platinum-based chemotherapy could bring under control life-threatening complications in hereditary TNBC and, therefore, it should be administered without hesitation in emergency circumstances if the patient can tolerate one dose of the medication.

Categories: General Surgery, Oncology

Keywords: breast cancer, platinum-based chemotherapy, response to chemotherapy, chemotherapy, neoadjuvant chemotherapy, triple negative breast cancer, hereditary breast cancer, bleeding breast cancer, breast cancer local control

\section{Introduction}

According to the World Health Organization (WHO), breast cancer is the most common cancer in women worldwide. It is estimated that more than 1.7 million new cases and 0.5 million breast cancer deaths occurred among women worldwide in 2012. In developed countries, due to population-based screening programs, the majority of cases are diagnosed

Received 05/25/2017 Review began 06/14/2017 Review ended 07/05/2017 Published 07/10/2017

\section{(c) Copyright 2017}

Irmejs et al. This is an open access article distributed under the terms of the Creative Commons Attribution License CC-BY 3.0., which permits unrestricted use, distribution, and reproduction in any medium, provided the original author and source are credited. in the early stage [1]. However, a significant proportion of patients present with advanced stage disease where treatment options are limited and achieving satisfactory results can be challenging for clinicians.

This case report is about a 50-year-old female patient with hereditary triple-negative breast cancer (TNBC) who did not comply with initial chemotherapy and, six months later, reappeared in the emergency room with severe anaemia resulting from a bulky, ulcerated, and actively bleeding tumor.

\section{Case Presentation}

This 50-year-old patient initially presented in August 2016 complaining of a lump in her right

\section{How to cite this article}

Irmejs A, Loza P, Skuja E, et al. (July 10, 2017) Platinum-Based Chemotherapy Secures Effective Local Control for Very Advanced Hereditary Triple-Negative Breast Cancer with Life-Threatening Bleeding. Cureus 9(7): e1455. DOI 10.7759/cureus.1455 


\section{Cureus}

breast for approximately one year. Family history included ovarian cancer (sister, diagnosed at age 52) and breast cancer (sister of father, diagnosed at age 65). She had been postmenopausal since age 49 and her previous mammogram in August 2015 did not indicate any abnormalities.

At the time of initial presentation, the cancer in her right breast was already locally advanced. Ultrasound examination of right axilla showed at least three specific lymph nodes. Fine needle aspiration (FNA) from suspicious contralateral left-sided axillary lymph node was negative. Core biopsy confirmed infiltrative ductal carcinoma, Grade 3 with focal necrosis, estrogen receptor (ER) negative, progesterone receptor $(\mathrm{PR})$ negative, and human epidermal growth factor receptor 2 (HER2) negative. Genetic testing for three locally common breast cancer susceptibility gene 1 (BRCA1) mutations (4153delA, C61G, 538insC) was negative. The patient was recommended to undergo complete BRCA1/2 gene testing, but so far has not performed it. One potential reason is that complete BRCA1/2 gene testing in Latvia has no public funding and the patient herself has to cover all costs. However, the patient has a strong family cancer history matching the diagnostic criteria for hereditary breast ovarian syndrome. The probability of finding BRCA1/2 gene mutation is reasonably high, and regardless of genetic test results, this should be considered as a hereditary breast cancer [2].

The decision was to commence treatment with neoadjuvant chemotherapy; however, the patient failed to attend the oncology clinic for her scheduled treatments.

Six months later, in February 2017, she presented in the emergency room with symptoms of severe anaemia (blood haemoglobin 3,7 g/dL), Physical examination revealed bulky (7 X 15 $\mathrm{cm}$ ), ulcerated, and actively bleeding carcinoma, eroding most of medial part of the right breast. The lesion was fixed to the chest wall and was producing an offensive smell (Figure 1).

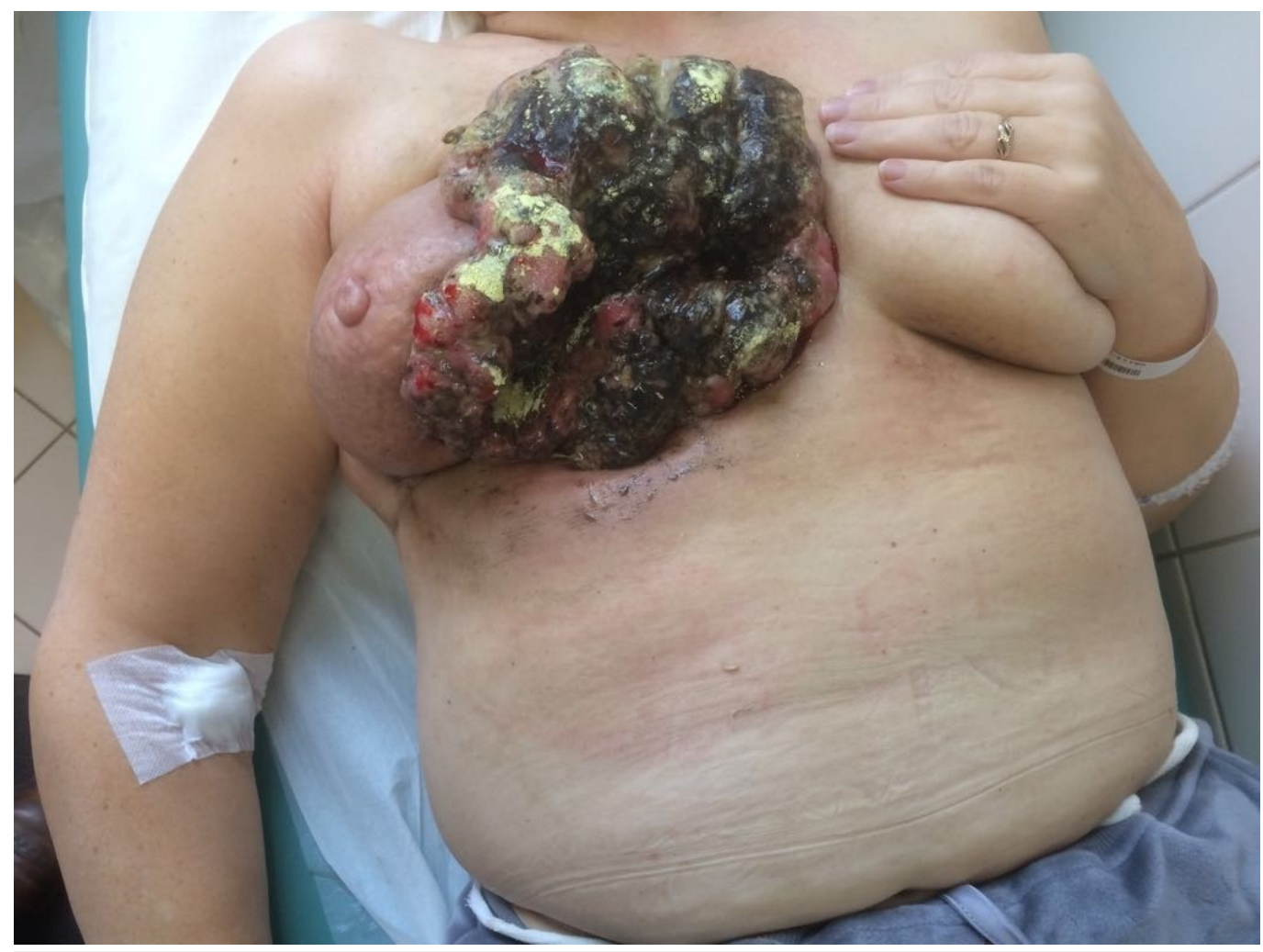

FIGURE 1: Picture of tumor before treatment 


\section{Cureus}

Apart from carcinomatous intoxication, her general condition was relatively stable and hemodynamics were stable. She was administered eight units of blood and four units of fresh frozen plasma (FFP). Bleeding was temporarily controlled by a pressure bandage.

A chest computed tomography (CT) scan in February 2017 showed a large infiltrative tumor mass adherent to chest wall muscles and the cartilage of the fourth rib and sternum (Figure 2). The right internal mammary vessels were involved. Mediastinal lymphadenopathy with multiple lymph nodes up to $1 \mathrm{~cm}$ in diameter were detected. Moreover, multiple (at least five) specific right axillary nodes up to $1.5 \mathrm{~cm}$ in diameter were present. A small amount of pleural effusion on the right side was diagnosed. A bone scan showed no abnormality. The blinical stage was T4cN3bMx (TNM classification for staging of breast cancer according to NCCN guideline V 1.2016). As no bone, lung, and liver metastasis were confirmed, we cannot completely rule out that mediastinal lymph nodes were unspecific; hence, $M$ stage is questionable.

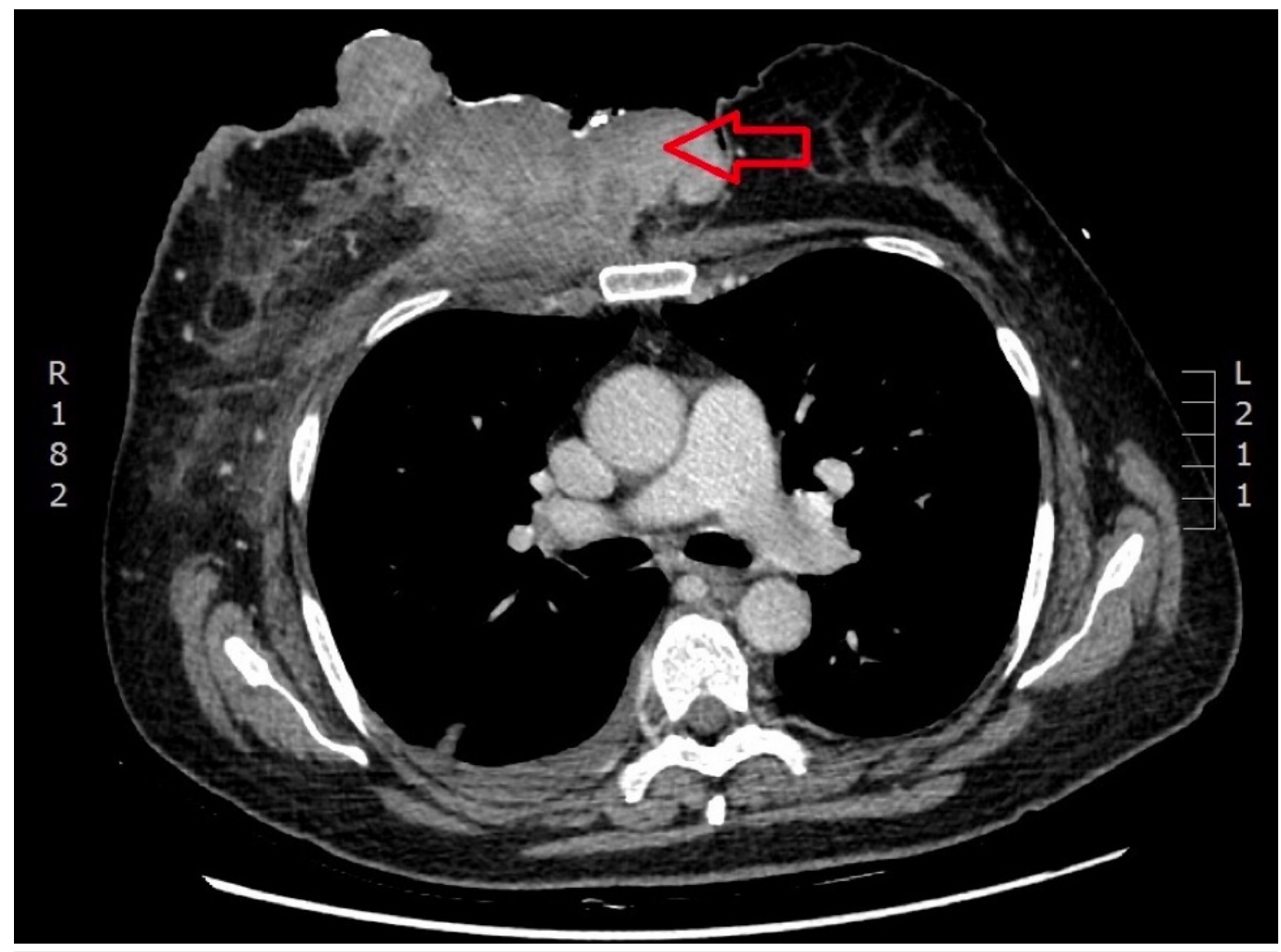

FIGURE 2: CT scan before treatment

Large tumor mass fixed to the chest wall (arrow)

Tumor marker carcinoma antigen 125 (CA-125) was elevated (49.7 U/mL); however, markers CA 15-3 and carcinoembryonic antigen (CEA) were within normal range.

Because of repeated severe bleeding episodes during change of dressings and the offensive smell, which extended ouside the ptient's room, immediate measures were indicated for life saving and hygienic purposes. The general surgeons in charge considered surgical removal, but it was rejected by the breast surgeon because surgical intervention would result in an extensive chest wall defect which would then require autologous flap reconstruction. This caries high risk of severe complications and should be considered only after failure of systemic therapy. Moreover, the patient's general condition was relatively poor and M stage was inconclusive. 


\section{Cureus}

The option of arterial embolisation was proposed by the breast surgeon, but it was rejected by the invasive radiologist, because at that particular moment there was no active arterial bleeding.

Ten days after admission to the hospital, neoadjuvant chemotherapy with three-week intervals of doxorubicin $60 \mathrm{mg} / \mathrm{m}^{2}$ and carboplatin in dose AUC-5 (area under the plasma concentration time curve) was commenced.

After just two cycles of chemotherapy, there was unexpectedly rapid clinical response and effective control of local symptoms (Figure 3). The tumor gradually shrunk to the centre with healthy skin forming from the periphery.

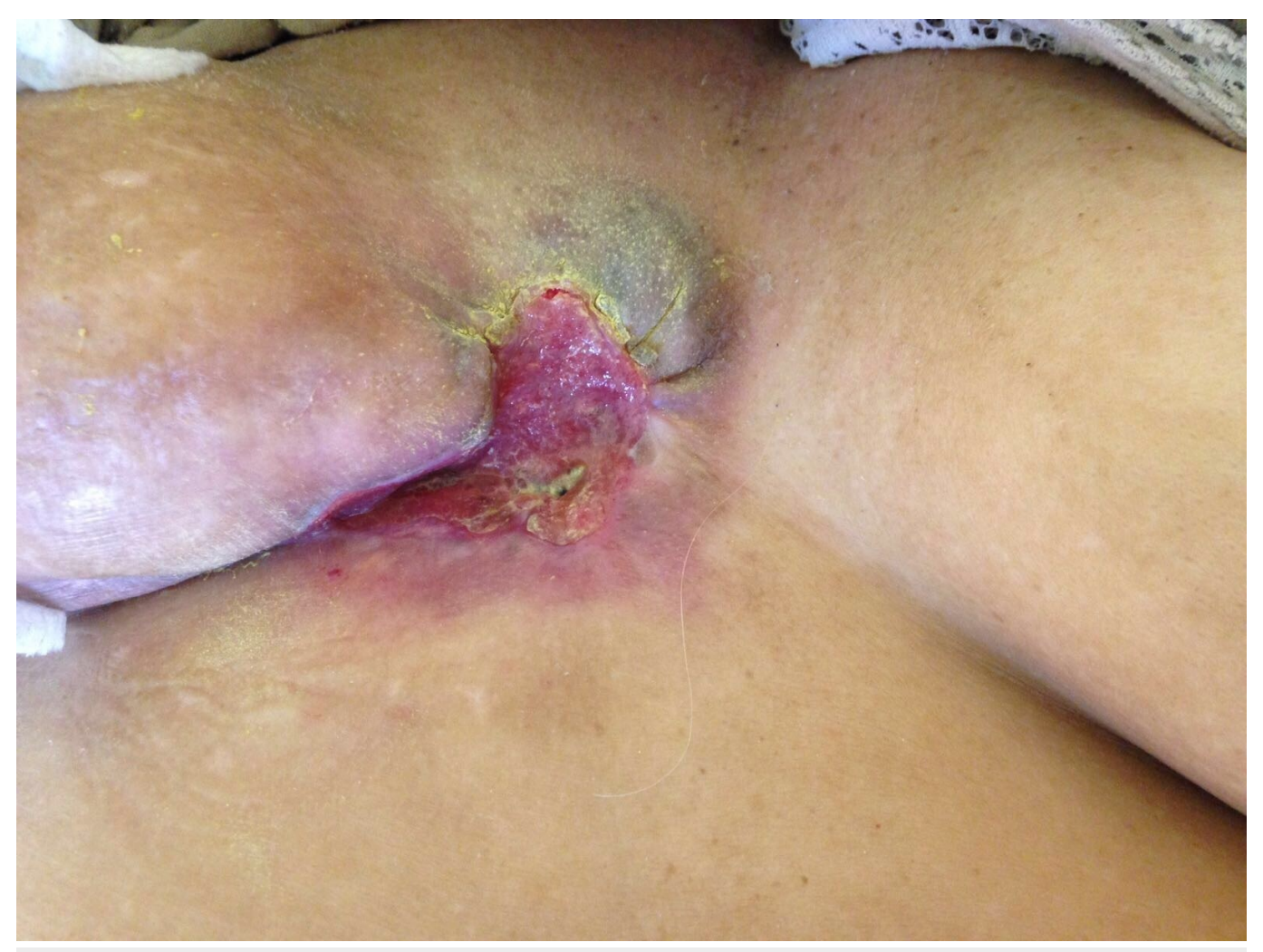

FIGURE 3: Picture of tumor after two cycles of chemotherapy

Repeated CT chest/abdomen scans in April 2017 indicated marked remission of the primary tumour, complete remission of mediastinal lymphadenopathy, and no radiologic evidence of any other distant metastasis (Figure 4). However, specific right axillary lymphadenopathy remained present. 


\section{Cureus}

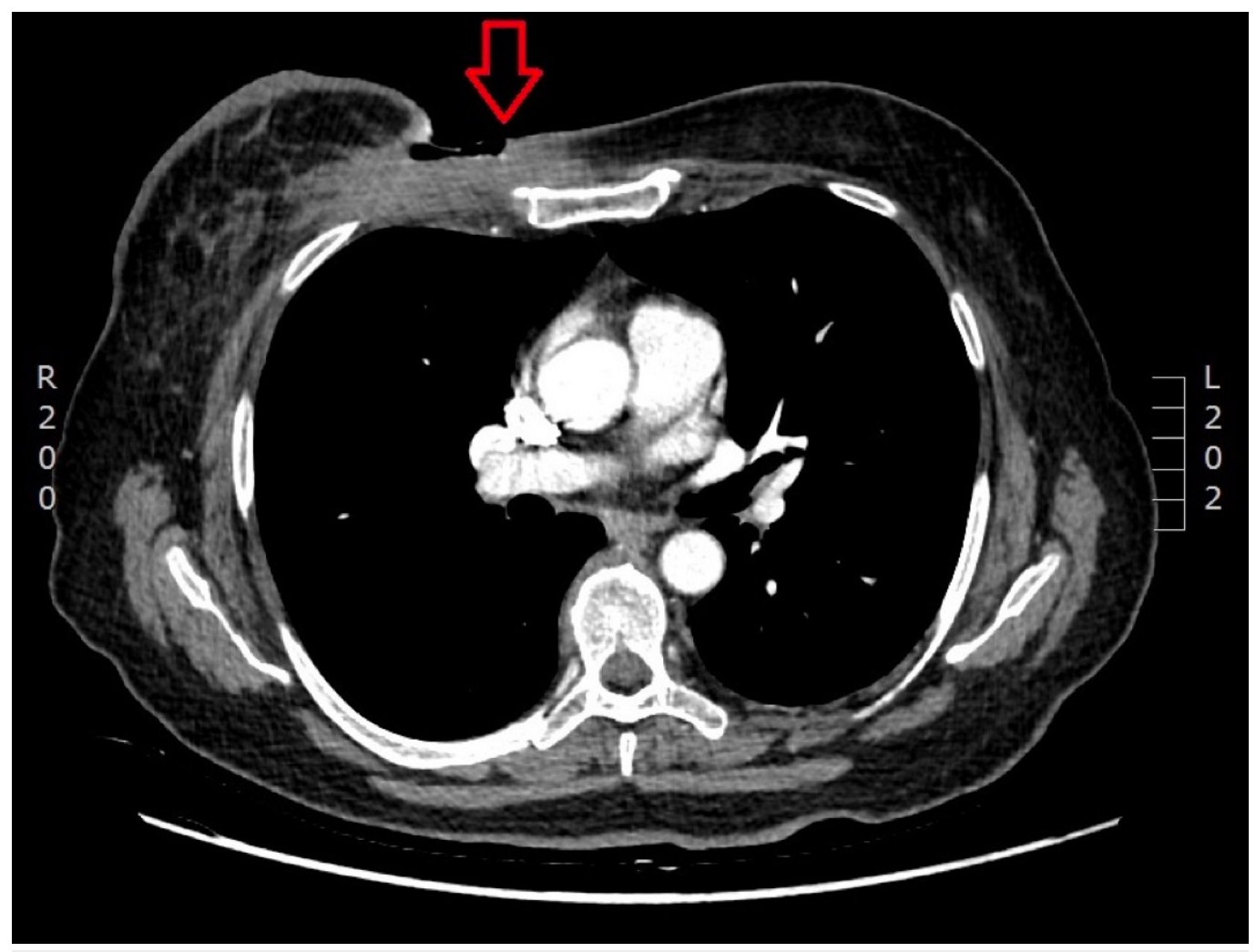

FIGURE 4: CT scan after two cycles of chemotherapy

The primary bulky tumor has significantly reduced in size (arrow)

We are currently eager, waiting for further loco-regional remission as the patient continues with chemotherapy. Afterwards, surgery and RT will be considered for further local control.

\section{Discussion}

From a historical perspective, surgery has been the method of choice for local control (including hygienic purposes) of advanced breast cancer. Over the last decades, increasing evidence has emerged on the role of systemic therapy for the local control of the disease. The role of chemotherapy and endocrine therapy in local control of advanced breast cancer is well documented [3]. However, the use of platinum-based therapies for treatment of TNBC in patients with strong family cancer history and/or BRCA1/2 mutations is a relatively recent development. There are several reports on the effectiveness of cisplatinum use in the metastatic and neoadjuvant setting for BRCA1 positive breast cancer that are consistent with our report [4-6]. Also, recent evidence from systematic reviews and meta-analysis of randomised-controlled trials suggest the benefits of adding platinum to conventional anthracycline-based chemotherapy in patients with locally advanced and metastatic TNBC [7]. In case of TNBC, platinum-based therapy is associated with significantly higher complete pathologic response rates, which is believed to be an independent indicator of response to treatment as well as overall prognosis [8]. However, further research is mandatory to support these findings.

Authors Ishizuna K, et al. [9] have reported two cases of locally advanced TNBC where bleeding from tumor and local control was achieved with chemotherapy plus targeted agents (weekly paclitaxel plus bevacizumab). 
To the best of our knowledge, this is the first report in the literature on the use of platinumbased chemotherapy for control of life threatening bleeding in case of T4c (TNM classification for staging of breast cancer according to NCCN guideline V 1.2016) advanced hereditary triplenegative breast cancer.

In our case, the interval between admission to hospital and initiation of chemotherapy was 10 days. This is a relatively short period of time; however, in view of the significant and disturbing symptoms which affected not only the patient herself but also other patients and hospital staff, retrospectively we admit that this period could have been even shorter.

\section{Conclusions}

Our case of exceptional responder raises several hypothesis that should be confirmed by a larger series: 1) platinum-based therapy could be effective for very advanced TNBC with strong family cancer history and/or BRCA1/2 mutation; 2) even a single course of chemotherapy could bring under control life-threatening complications and therefore should be administered without hesitation in those circumstances, providing the patient can tolerate one dose of the medication.

\section{Additional Information \\ Disclosures}

Human subjects: Consent was obtained by all participants in this study. Conflicts of interest: In compliance with the ICMJE uniform disclosure form, all authors declare the following:

Payment/services info: All authors have declared that no financial support was received from any organization for the submitted work. Financial relationships: All authors have declared that they have no financial relationships at present or within the previous three years with any organizations that might have an interest in the submitted work. Other relationships: All authors have declared that there are no other relationships or activities that could appear to have influenced the submitted work.

\section{Acknowledgements}

This study was supported by State Research Program "Biomedicine for the public health (BIOMEDICINE)" project 5 "Personalised cancer diagnostics and treatment effectiveness evaluation".

\section{References}

1. IARC: World Cancer Report 2014. Bernard W Stewart and Christopher P Wild (ed): WHO, 2014. 362-6.

2. Nilsson MP, Winter C, Kristoffersson U et al.: Efficacy versus effectiveness of clinical genetic testing criteria for BRCA1 and BRCA2 hereditary mutations in incident breast cancer. Fam Cancer. 2017, 16:187-193. 10.1007/s10689-016-9953-x

3. Wang M, Hou L, Chen M et al.: Neoadjuvant chemotherapy creates surgery opportunities for inoperable locally advanced breast cancer. Sci Rep. 2017, 22:44673. 10.1038/srep44673

4. Byrski T, Dent R, Blecharz P, Foszczynska-Kloda, et al.: Results of a phase II open-label, nonrandomized trial of cisplatin chemotherapy in patients with BRCA1-positive metastatic breast cancer. Breast Cancer Res. 2012, 14:1. 10.1186/bcr3231

5. Byrski T1, Gronwald J, Huzarski T, et al.: Pathologic complete response rates in young women with BRCA1-positive breast cancers after neoadjuvant chemotherapy. J Clin Oncol. 2010, 28:375-9. 10.1200/JCO.2008.20.7019

6. Byrski T, Huzarski T, Dent R, et al.: Pathologic complete response to neoadjuvant cisplatin in BRCA1-positive breast cancer patients. Breast Cancer Res Treat. 2014, 147 :401-5.

10.1007/s10549-014-3100-X 


\section{Cureus}

7. Guan X1, Ma F, Fan Y, Zhu W, Hong R, Xu B: Platinum-based chemotherapy in triple-negative breast cancer: a systematic review and meta-analysis of randomized-controlled trials.. Anticancer Drugs. 2015, 26:894-901. 10.1097/CAD.0000000000000260

8. Petrelli F1, Coinu A, Borgonovo K, Cabiddu M, Ghilardi M, Lonati V, Barni S: The value of platinum agents as neoadjuvant chemotherapy in triple-negative breast cancers: a systematic review and meta-analysis. Breast Cancer Res Treat. 2014, 144:232-32. 10.1007/s10549-0142876-z

9. Ishizuna K, Ninomiya J, Ogawa T, et al.: Locally advanced breast cancer with bleeding - two cases effectively treated with bevacizumab plus weekly paclitaxel. Gan To Kagaku Ryoho. 2014, 41:637-40. 